\title{
The Development, Challenges and Management of Groundwater in Rural China
}

\author{
JinXia Wang ${ }^{1}$, JikUn Huang ${ }^{1}$, Amelia Blanke ${ }^{2}$, QIUQIONG \\ HUANG $^{2}$ AND SCOTT ROZELLE ${ }^{2}$
}

${ }^{1}$ Center for Chinese Agricultural Policy, Institute of Geographical Sciences and Natural Resources Research, Chinese Academy of Sciences, Jia 11 Datun Road, Anwai, Beijing 100101, PR China; '2Department of Agricultural and Resource Economics, University of California, Davis, CA 95616, USA

\section{Introduction}

The history of groundwater in China is one of extremes, or apparent extremes. Before the 1960s, the story was one of neglect; only a small fraction of China's water supply came from groundwater (Nickum, 1988). Almost none of the Ministry of Water Resource's investment funds were allocated to the groundwater sector until the late 1960s. Certainly, to the extent that underground water resources were valuable, China was ignoring a valuable resource.

Since the mid-1970s, however, the prominence of the groundwater sector has risen dramatically. Over the last 30 years, agricultural producers, factory managers and city officials - far from ignoring groundwater resources - have entered an era of exploitation (Smil, 1993; Brown and Halweil, 1998). Arguably, there have been more tube wells sunk in China over the last quarter century than anywhere else in the world. As a share of total water supply, groundwater has risen from a negligible amount across most of China to being a primary source of water for agriculture, industry and domestic use in many of the nation's most productive regions. Unfortunately, the resulting fall in groundwater tables has been one of China's most serious environmental problems (World Bank, 1997).

Despite the rise in importance of the sector, and the threats to its continuation, relatively little systematic information is available about many key aspects of China's groundwater economy in rural areas. That is not to say that there is a shortage of scientific research studies that document some of China's groundwaterrelated problems, for example, land subsidence, salt water intrusion and overdrafts (Chen et al., 2003; Sakura et al., 2003). Moreover, there is recent work on groundwater usage and quality in China's cities (Tang, 1999). However, with the exception of a number of general summary pieces that are based primarily on anecdotes and 
secondary citations (e.g. Nickum, 1988, 1998; Lohmar et al., 2003) and papers that look at groundwater use in relatively isolated agricultural areas (e.g. Kendy et al., 2004; Wang et al., 2005, 2006), there is little work based on original data that is sufficiently broad in scope to give the reader a general overview of the groundwater economy and its challenges and management, especially in rural areas.

The primary goal of this chapter is to overcome the absence of research on China's groundwater economy. We will pursue three specific objectives. First, we will characterize China's groundwater resources, briefly reviewing the main physical and geographic properties of northern China's groundwater resource development, describing the role of groundwater in the economy and examining the technology that producers are using to extract and utilize the resource. Second, we will examine the main problems that the sector is facing, including falling groundwater levels and deteriorating water quality. Finally, we will document responses of the major water stakeholders in China's agricultural sector - the government and agricultural producers - focusing primarily on the emergence of institutions as a response to some of these problems. Our findings draw primarily on two data-sets that we collected ourselves, covering nearly 450 communities in northern China.

Due to the broad nature of the issues dealt with in this chapter, we will narrow the scope of our analysis in several ways. First, we will limit our examination to northern China, the region that uses the majority of China's groundwater. In our study, northern China can be thought to include the following regions: north China (huabei), north-east China (dongbei) and north-west China (xibei). Our sample communities also represent all or part of four major river basins: the Hai River basin, the lower and middle reaches of the Yellow River basin, the northern bank of the Huai River basin and the Songliao River basin in the north-east. Although we use our data to extrapolate to the entire northern China region (12 provinces and 2 municipalities), most of our data come from six provinces - Liaoning, Hebei, Henan, Shanxi, Inner Mongolia and Shaanxi. ${ }^{1}$ Since agriculture is the main waterusing sector (68\% in 2001; Ministry of Water Resources, 2002), our data-set was collected from rural communities, and we will focus on the use of water for agriculture. $^{2}$ We also explicitly exclude all wells in our sample villages that are used solely for drinking water.

\section{Data}

In addition to national statistics, our analysis is based on data that we collected as part of two recent surveys specifically designed to address irrigation practices and agricultural water management. The China Water Institutions and Management (CWIM) survey of September 2004 was the second round of a panel survey, the first phase of which was conducted in 2001 (Fig. 3.1). Enumerators conducted surveys of community leaders, groundwater managers, surface water irrigation managers and households in 48 villages in Hebei and Henan provinces. The villages were chosen according to geographic properties. In Hebei, villages were chosen from counties near the coast, near the mountains and in the central region between the mountains and the coast. In 


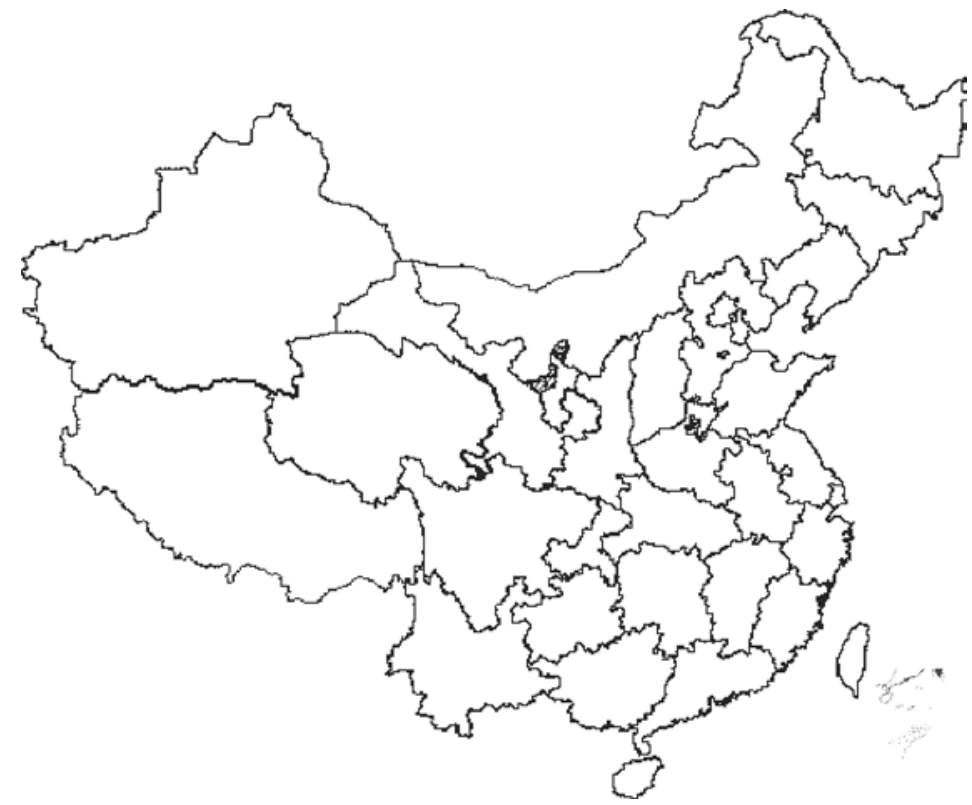

Fig. 3.1. Fourteen counties surveyed in China in September 2004. (From China Water Institutions and Management (CWIM) survey.)

Henan, villages were chosen from counties bordering the Yellow River and from counties in irrigation districts at varying distances from the Yellow River.

We conducted a second survey, the North China Water Resource Survey (NCWRS), in December 2004 and January 2005 (Fig. 3.2). This survey of village leaders from 400 villages in Inner Mongolia, Hebei, Henan, Liaoning, Shaanxi and Shanxi provinces used an extended version of the community-level village instrument of the CWIM survey. Using a stratified random sampling strategy for the purpose of generating a sample representative of northern China, we first sorted counties in each of our regionally representative sample provinces into one of four water scarcity categories: very scarce, somewhat scarce, normal and absolutely scarce (mountain/desert). ${ }^{3}$ We randomly selected two townships within each county and four villages within each township. In total, combining the CWIM and NCWRS surveys, we visited approximately 6 provinces, 60 counties, 126 townships and 448 villages.

The scope of the surveys was quite broad. Each of the survey questionnaires included more than ten sections. Among the sections, there were those that focused on the nature of China's rural water resources, the common types of well and pumping technology. There also were several sections that examined the most important water problems, government water policies and regulations as well as a number of institutional responses (e.g. tube well privatization). Although sections of the survey covered both surface and groundwater resources, we will focus mostly on those villages that have groundwater 


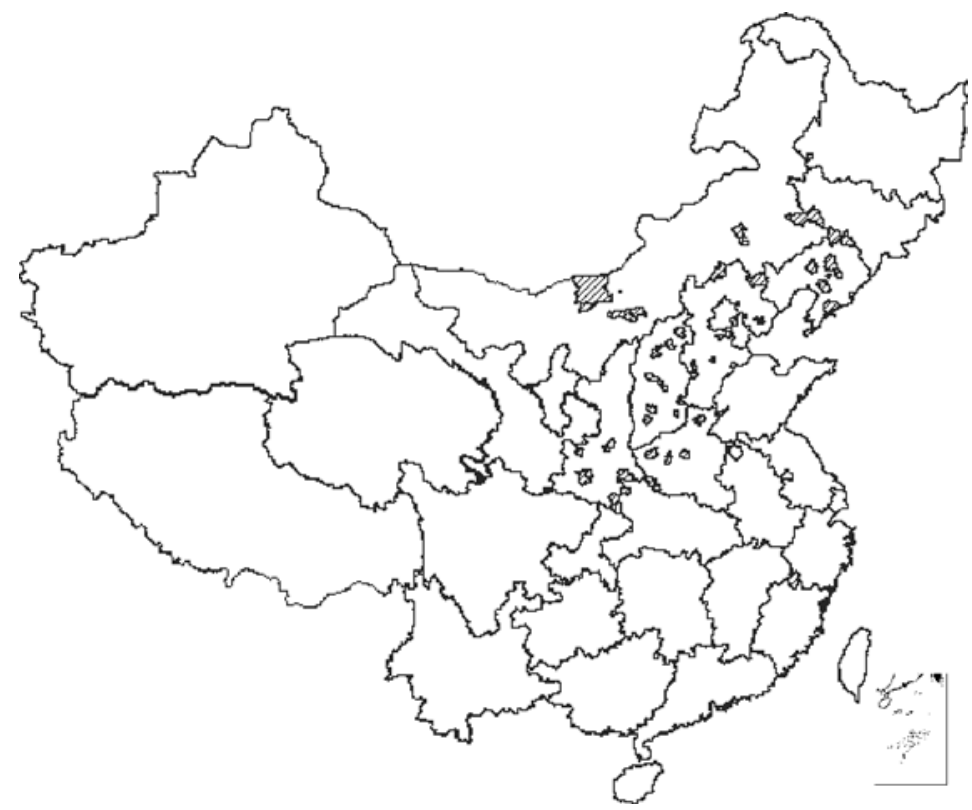

Fig. 3.2. Fifty counties surveyed in December 2004 and January 2005. (From North China Water Resource Survey (NCWRS).)

resources (in some cases, even if they were not being used). The survey collected data on many variables for 2 years - 1995 and 2004 - asking about conditions back in time. By weighting our descriptive and multivariate analysis with a set of population weights, we were able to generate point estimates for all of northern China. ${ }^{4}$

\section{China's Groundwater Resources}

While China's water resources are substantial compared with those of many other countries, its population is even larger, and its water resources are not evenly distributed across the country or across important agricultural regions. China ranks fifth in total water resources among the countries of the world. On a per capita basis, however, its water resource availability is among the lowest. Moreover, the nation's water resources are overwhelmingly concentrated in southern China; northern China has only approximately $25 \%$ of the water endowment of the south and $10 \%$ of the world average (Ministry of Water Resources, 2000). The lower levels of rainfall in northern China are also much more seasonal than in the south, with more than $70 \%$ of the rain occurring between June and September. Northern China, however, remains an important agricultural region and the site for much of China's industrial production. Although it has only $24 \%$ of the nation's water resources, northern China contains more than $65 \%$ of China's cultivated land and produces roughly half of its grain (nearly all of its wheat and maize) and more than $45 \%$ of the nation's 
gross domestic product (China National Statistical Bureau, 2000; Ministry of Water Resources, 2000).

Groundwater resources in China are both unevenly distributed and unevenly used across regions. According to the latest estimates generated by the Ministry of Land Resources, the annual natural recharge of fresh groundwater resources in China is 884 billion cubic meters, about one-third of the nation's total water resources (Ministry of Land Resources, 2005). Of this, about 70\% are in southern China, and only about $30 \%$ in northern China. However, the intensity of groundwater use occurs in a very different pattern. Of all the known groundwater resources, rural and urban users are using more than $70 \%$ in northern China, whereas less than $30 \%$ of the known groundwater resources in southern China are being used.

Despite the fact that most groundwater resources are located in southern China, it is fortunate that they exist across wide expanses of northern China's river basins and that these resources are relatively abundant and accessible. Alluvial deposits consisting primarily of sand, loess silt and clay extend to a depth of more than $500 \mathrm{~m}$ below the surface in some areas (Kendy et al., 2003). These deposits comprise the aquifers that supply groundwater to regions in all major river basins in the North China Plain. The aquifers, however, vary greatly across northern China. For example, in the North China Plain, unlike the south where villages in mountainous areas can tap groundwater resources, mountainous areas are often groundwater-deficient. ${ }^{5}$ In the flat plains, the aquifers are multilayered. The multilayered aquifers in the Hai River basin (NCP) typically have $2-5$ layers; the first and third layers are the most water-abundant. The first layer is typically an unconfined aquifer made up of large-grained homogeneous sand and gravel. The other layers are typically confined aquifers. In some areas, especially in the eastern parts of the Hai River basin, there is a naturally occurring saline layer. Created during a previous ice age, the second layer often contains saline water, is confined and has a salt content high enough that it is typically unusable for agriculture without treatment.

\section{Groundwater resources from the farmer's perspective}

To obtain an understanding of how farmers view their water resources, we asked village leader respondents to describe the nature of the aquifers that are under their villages. Because most village leaders have not been a part of any hydrogeological surveys, they often were not able to answer questions concerning the existence, size or other geological properties of the aquifers. Instead, village leaders knew more precisely how many shallow and deep wells there were in their village as well as the depths of those wells. Although there is no complete correlation between the depth of the wells and the nature of the aquifer, in many cases, the existence of shallow or deep wells coincides with that of shallow or deep layers of village aquifers. Regardless of their exact hydrogeological properties, according to our data (and the perception of village leaders), 'deep wells' are almost always having a depth of at least $60 \mathrm{~m}$. If a village needs to drill through an aquitard (a clay layer in most cases) to sink a 
well, the well is always defined as a 'deep well'. Shallow wells, in contrast, are mostly less than $60 \mathrm{~m}$ and do not penetrate an aquitard.

Whether deep or shallow, groundwater resources are extensive across regions of northern China. We asked village leaders if there were groundwater resources in the village. Most replied that there were, and the share of villages having these was almost $95 \%$ in 2004 . However, not all villages having groundwater use this resource for irrigation. In 2004, more than $15 \%$ of irrigated villages with groundwater did not use it for irrigation. We further explore the reason behind this. According to the village leader respondents, there were two major reasons for not using it. Research results show that in 2004, the most important reason was that there were cheap and sufficient surface water resources (51\% of villages). The second important reason was that there was no money to dig tube wells (37\% of villages). Such findings suggest that there still may be potential to use greater volumes of groundwater resources in the future. With increasing water scarcity and rising water demands, more villages have begun to use their community's groundwater. For example, from 1995 to 2004, the share of villages using groundwater resources for the first time had increased by almost $12 \%$.

Relying on the observations of our NCWRS respondents, one of our most prominent findings was the great diversity of aquifer development in northern China. Of the 238 sample villages that used groundwater for irrigation in 2004, $33 \%$ told us that they extracted groundwater only from shallow aquifers, $42 \%$ only from deep aquifers and the remaining 25\% from both. Our data show that in some villages in northern China, the groundwater supply from shallow aquifers is sufficient to support current local water demand for irrigation. In other villages, maybe due to exhausted or unusable shallow aquifers, farmers extract groundwater only from deep aquifers. ${ }^{6}$ In some villages (25\%), both shallow and deep aquifers are being used. The groundwater supply from shallow unconfined aquifers is highly dependent upon precipitation, which supplies groundwater recharge. When rainfall is above average, as it was in 2004, water levels increase in shallow aquifers due to above-average recharge. This may be the reason that more villages extracted groundwater from shallow aquifers in 2004 than in $1995 .^{7}$

According to our respondents, the depth to water also varied across northern China. Although the average depth to water in 2004 was $26 \mathrm{~m}$, it varied sharply across our sample villages (Fig. 3.3). In fact, in most villages depth to water was fairly shallow. In 2004, the average depth to water for the villages from the shallowest quartile of villages was only $4 \mathrm{~m}$ and that for the second quartile was only $9 \mathrm{~m}$. Villages in the third quartile were pumping from an average depth to water of more than $30 \mathrm{~m}$. In only $4 \%$ of groundwater villages were villagers pumping from more than $100 \mathrm{~m}$.

\section{The contribution of China's groundwater}

After the emergence of the tube well, and diesel and electric pumping technology, the role of groundwater rapidly grew in importance for all uses (Wang et al., 


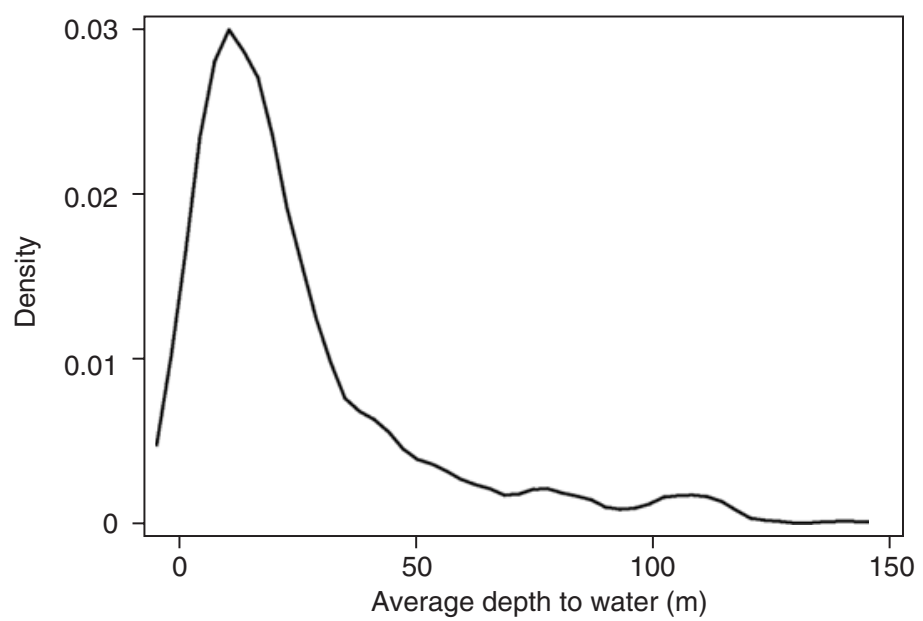

Fig. 3.3. Average depth to water in 2004. (From authors' survey in 2004.)

2005). In total, the use of groundwater rose from almost zero in the 1950s to 57 billion cubic meters annually in the 1970s. After the rural economic reforms in the late 1970s and early 1980s (which, among other things, shifted income and control rights from the collective to the individual household), groundwater use continued to rise, reaching 75 billion cubic meters in the 1980s and more than 100 billion cubic meters after 2000 (Ministry of Land Resources, 2005). ${ }^{8}$ As the use of groundwater rose nationally, its share in the nation's water supply also rose (from almost nothing in the 1950s to a major fraction now). Across China, groundwater currently supplies about $20 \%$ of China's water. However, this amount is unevenly distributed. In southern China, groundwater comprises approximately $14 \%$ of water supply; in northern China it supplies $49 \%$. From this point of view, the rise of the accessibility of groundwater has certainly played an important role in the emergence of northern China's regional economy.

Although the importance of groundwater has risen for all uses, it is likely that, as with water resources in general, groundwater resources are being increasingly allocated for non-agricultural uses. ${ }^{9}$ Unfortunately, China does not systematically collect data on water allocation to economic uses by type of water resource. As a consequence, all we know are the shares of total water resources that are going for domestic, industrial and agricultural uses. Since much of the increase in water use over the last 20 years has come from groundwater, we believe it is safe to assume that the share of groundwater being allocated to domestic and industrial uses follows a somewhat similar pattern to that followed by water resource use in general. Although in 1978, only $1 \%$ of China's water use was allocated for domestic use, by 2002 about $11 \%$ of water went for domestic users (Table 3.1). The use of water for industry also rose from $14 \%$ in 1978 to more than $21 \%$ in 2002 . Although the share of water used in agriculture has fallen (from $85 \%$ in 1978 to $68 \%$ in 2002), it is still the largest water user. 
Table 3.1. Uses of water resources in China, 1978 to 2002. (From Ministry of Water Resources, 2002.)

\begin{tabular}{lccc}
\hline & Domestic (\%) & Industrial (\%) & Agriculture (\%) \\
\hline Total water resources & 1 & & \\
$\quad 1978$ & 10 & 14 & 85 \\
1997 & 11 & 21 & 69 \\
2002 & & 21 & 68 \\
Groundwater resources & 26 & 20 & 54 \\
$\quad 1997$ & & & \\
\hline
\end{tabular}

\section{Irrigation and the role of groundwater}

Our data also demonstrate the importance of groundwater in supplying irrigation to northern China's agricultural sector. According to the respondents, nearly half $(49 \%)$ of China's cultivated area is irrigated (slightly higher than the figure given in China National Statistical Bureau, $2004-42 \%$ ). However, with our data we can understand the water economy more fully, since our survey covers more than what is available in official sources. For example, since national statistics do not collect irrigation data by type of irrigation water, we asked village leaders to carefully document the source of their irrigated area: either surface, groundwater or conjunctive use of both. On the basis of their responses, in 1995, of all of the cultivated land that is irrigated, only $40 \%$ came from surface water diversions (or was lifted from canals by pumps onto the fields). The remaining 60\% came from groundwater sources. Between 1995 and 2004 the importance of groundwater has continued to grow. In 2004, 68\% of irrigation in northern China was from groundwater.

\section{Crop-specific incidences of irrigated area}

Our data can also produce estimates of crop-specific sown area statistics by irrigated and non-irrigated portions. For example, major food grains in northern China are mostly irrigated (Table 3.2). Approximately $96 \%$ of rice and $80 \%$ of wheat are irrigated, levels that are above the national average (Table 3.2, column 1, rows 1 and 2). Hence, our data support the findings of Huang et al. (2006) that investment in irrigation has been central for China to maintain food security. Although it is well known that China's food crops are heavily irrigated and that this is an important factor in China being able to produce a large fraction of its own food, these crop-specific estimates are important because China's own statistical bureau does not report sown area by irrigated and nonirrigated portions.

In contrast to the case of food grains, a majority of feed grains and lowervalued staple crop area is not irrigated (Table 3.2, column 1, rows 3,5 and 6). For example, despite its growing importance in China's agricultural economy, only $49 \%$ of China's maize is irrigated. ${ }^{10}$ An even lower proportion of coarse grains and potatoes (including white and sweet potatoes) is irrigated. Although the proportion of irrigated area in cash crops also varies by crop, much of the 
Table 3.2. Share of irrigated sown area by crop type in north China. (From authors' survey in 2004.)

\begin{tabular}{lccc}
\hline & $\begin{array}{c}\text { Percent of cropland } \\
\text { that is irrigated }\end{array}$ & \multicolumn{2}{c}{ Percent of irrigated sown area } \\
\cline { 3 - 4 } Crop & 96 & Surface water & Groundwater \\
\hline Rice & 80 & 76 & 24 \\
Wheat & 49 & 30 & 72 \\
Maize & 58 & 30 & 70 \\
Cotton & 22 & 27 & 70 \\
Potato & 24 & 32 & 73 \\
Soybean & 47 & 38 & 67 \\
Oil crops & 66 & 33 & 62 \\
Field vegetables & & & 67 \\
\hline
\end{tabular}

area of China's main cash crops is irrigated (e.g. 58\% of cotton area, $47 \%$ of oil crop area and $66 \%$ of field vegetable area - Table 3.2, rows 4, 6 and 7).

Perhaps more importantly, in northern China irrigation for most crops mainly depends on groundwater resources (Table 3.2, column 3). For grains and other staple crops, except for rice, at least $70 \%$ of the producers in irrigated areas use groundwater resources ( $72 \%$ for wheat; $70 \%$ for maize; $73 \%$ for potatoes). For cash crops, groundwater is the major source of water for irrigation. For example, groundwater irrigates $70 \%$ of cotton area, $62 \%$ of oil crop area and $67 \%$ of field vegetable area.

\section{Developing China's Groundwater}

While the development of China's surface water resources has a long history and has played an important role in its growth as a state, the development of most groundwater resources has been compressed into less than 50 years. In this section, we briefly examine the way in which China has developed its groundwater resources by first describing the trends over the last 50 years in the installation of tube wells and pumps, focusing on the path of this development over time and across space. Because we have more detailed data from the last decade, much of the discussion will focus on the recent period. The second part of this section briefly introduces the technology that is being used.

\section{The rise of tube wells}

According to national statistics, the installation of tube wells began in the late 1950s and, although the number of wells has grown continuously, the pace of increase has varied from decade to decade (Ministry of Water Resources and Nanjing Water Institute, 2004). During the 1950s, the first pumps were introduced to China's agricultural sector. Although still fairly limited, the growth rate was fast. During the Great Leap Forward (the late 1950s and early 1960s), 
however, statistical reporting was suspicious and many irrigation projects that were started during the period were badly engineered and often abandoned. After the recovery from the Great Leap Forward and the famine that followed, statistical agencies recovered, and statistical series since the mid-1960s are relatively consistent.

Since the mid-1960s, the installation and expansion of tube wells across China has been nothing less than phenomenal. In 1965, it was reported that there were only 150,000 tube wells in all of China (Shi, 2000). Since then, the number has grown steadily. By the late 1970s, there were more than 2.3 million tube wells. After stagnating during the early 1980s, a time when irrigated area, especially that serviced by surface water, fell, the number of tube wells continued to rise. By 1997, there were more than 3.5 million tube wells; by 2003, the number rose to 4.7 million.

The path of tube well expansion shown in the official data is largely supported by the information we have from the NCWRS. During the survey we asked the village leaders to tell us about the initial year in which someone (either the village leadership or an individual farmer) in their village sank a tube well (Fig. 3.4). According to the data, we found that by 1960, less than $6 \%$ of villages had sunk their first tube well. Over the next 20 years, between the early 1960s and the onset of reform, the number of villages with tube wells rose to more than 50\%. During the next 10 years, between 1982 and 1992, the number of villages with tube wells rose by only $7 \%$. After the early 1990 , however, the pace of the expansion of groundwater accelerated, and by 2004 almost $75 \%$ of villages had wells and thus access to groundwater.

While the growth of tube wells reported by the official statistical system is impressive, we have reason to believe the numbers are far understated. According to the NCWRS, on average, each village in northern China contained 35 wells in 1995. When extrapolated regionally, this means that there

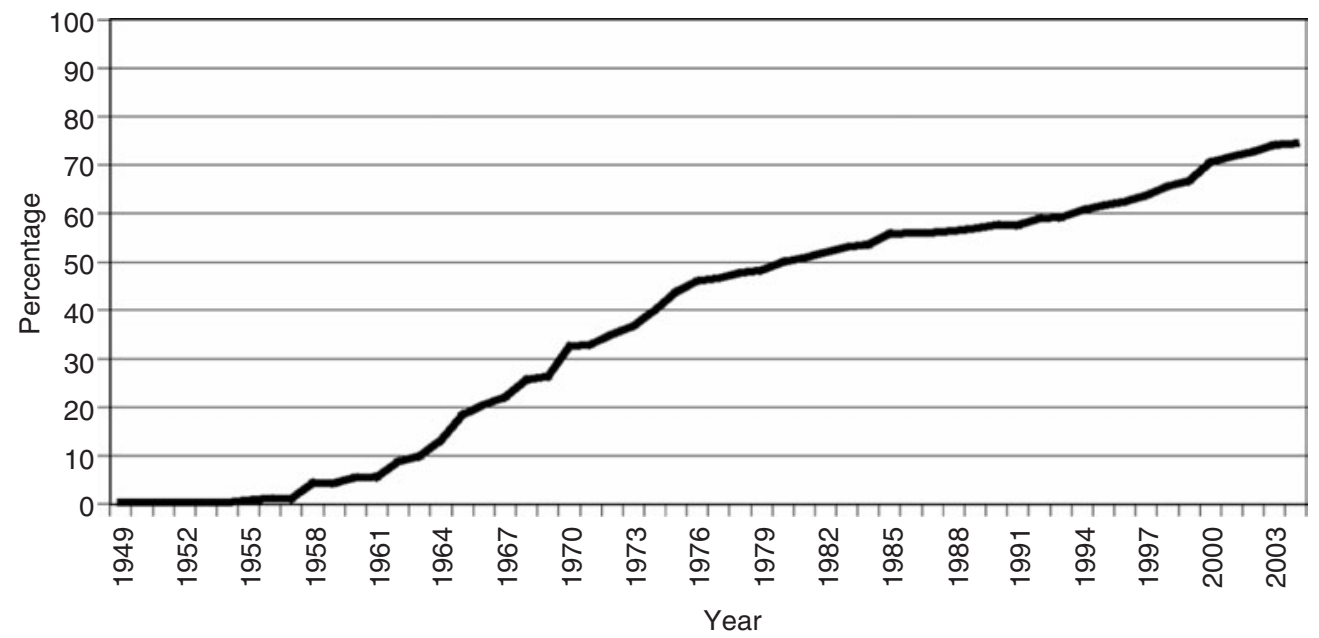

Fig. 3.4. Share of villages with wells over time. (From authors' survey in 2004.) 
were more than 3.5 million tube wells in the 14 provinces in northern China by 1995 . According to our data, there has been a rapid growth of wells. ${ }^{11}$ By 2004, the average village in northern China contained 70 wells, suggesting that the rise in tube well construction since the mid-1990s has been even faster than indicated by official statistics. By 2004, we estimate that there were more than 7.6 million tube wells in northern China. At least in our sample villages, the number of tube wells has grown by more than 12\% annually between 1995 and 2004.

\section{The technology that pumps China's water}

As China's groundwater usage has expanded, the characteristics of pumps used for shallow and deep wells have also evolved. In 1995, the average size of the pump used on a shallow well was 3 in., drawing $6.9 \mathrm{~kW}$ of power with a lift of $28 \mathrm{~m}$. The average shallow well pump discharged about $32 \mathrm{~m}^{3} / \mathrm{h}$. By 2004, the average pump increased marginally in size (to $3.1 \mathrm{in}$.), power (to $7.2 \mathrm{~kW}$ ), lift (31 m) and discharge (to $37.5 \mathrm{~m}^{3} / \mathrm{h}$ ).

The rate of change of deep well pumps was greater than that of shallow ones. In 1995, the average deep pump was $3.9 \mathrm{in}$. in diameter, drew $13.5 \mathrm{~kW}$ of power, had a lift of $53 \mathrm{~m}$ and discharged $61.2 \mathrm{~m}^{3} / \mathrm{h}$. By 2004, both power and lift had increased (to 14.1 and 58, respectively). Both diameter and discharge, however, decreased slightly (to 3.7 and 60.9 , respectively). ${ }^{12}$

The evolution of pump technology was mostly being driven by new technologies that were coming on the market and the demand for more powerful pumps. When we asked villages if they had changed the pumping technology type between 1995 and 2004, more than one quarter of villages using groundwater in 2004 responded that they had. Interestingly, although pumps are generally getting bigger and more powerful, they are not necessarily increasing in price. In fact, there is evidence that the price of pumps in China is falling. While we cannot pinpoint the reason why, it is likely due to an increase in economy of scale over the last decade. Our data show a general trend in purchasing location from government (state-owned) to private pump dealers.

\section{Groundwater Problems and Challenges}

As with most periods of rapid economic growth and intensive resource use, many problems arise. In the case of northern China, however, because of the importance of water, much attention has been focused on the sector's problems (Smil, 1993; Brown and Halweil, 1998; Ministry of Water Resources and Nanjing Water Institute, 2004). In fact, we believe there are many misperceptions about the nature of China's water problems - especially as they relate to the rural economy. In many cases, problems, although serious regionally, are not national in scope. Other problems are often confined to urban or rural areas, but not both. Of course, most of the misperceptions are not intentional, but a result of poor information. The goal of this section is to try to provide a 
brief assessment of the main problems facing China's groundwater economy. Given the fact that most of the work in the past has had an urban focus, our work centers on those problems affecting the rural sector.

\section{Overdrafting China's groundwater resources}

According to a comprehensive survey completed by the Ministry of Water Resource in 1996, the overdraft of groundwater was one of China's most serious resource problems (Ministry of Water Resources and Nanjing Water Institute, 2004). Although we do not know the exact way in which the survey was conducted, the results of the survey provide evidence that groundwater overdraft is a widespread problem and may be getting worse. According to the report, overdraft is occurring in more than 164 locations and affects more than $180,000 \mathrm{~km}^{2}$. The areas of overdraft range from $10-20 \mathrm{~km}^{2}$ to more than $10,000 \mathrm{~km}^{2}$, and are in 24 of China's 31 provinces. Groundwater overdraft is affecting all types of aquifers: the shallow groundwater table $\left(87,000 \mathrm{~km}^{2}\right)$, the deep groundwater table $\left(74,000 \mathrm{~km}^{2}\right)$ and the aquifers that have two layers, both the shallow and the deep $\left(13,000 \mathrm{~km}^{2}\right) .{ }^{13}$ Since the $1980 \mathrm{~s}$, the annual overdraft of groundwater has averaged about 7.1 billion cubic meters. In the late 1990s, the annual rate of overdraft exceeded 9 billion cubic meters. More than one-third of the volume of overdraft is from deep wells, many of which may be non-renewable on a short timescale.

Although the problem of overdraft is usually discussed in general, it appears to be particularly acute in cities. The Ministry of Land Resources has recently finished an evaluation of groundwater resources in China (Ministry of Land Resources, 2005). According to the final report, groundwater resources in most large and middle-sized cities in northern China are either in overdraft (extractions exceed recharge) or in serious overdraft conditions (the fall of the groundwater table exceeds $1.5 \mathrm{~m}$ /year). ${ }^{14}$ For example, in many cities the volume of water extracted from the aquifer is nearly double the volume of average annual recharge. ${ }^{15}$

Such dramatic numbers for all of China, especially for urban areas, are the cause of the concern that has appeared in the literature. However, when analysing the effect on rural areas, at least according to NCWRS data, a somewhat different picture arises. According to our data, there was no fall in the groundwater table in $25-33 \%$ of villages in northern China using groundwater in both 1995 and $2004 .{ }^{16}$ In $8.5-16 \%$ of villages (between one-third and one-half of villages that reported no fall in the groundwater table) respondents told the enumerators that the groundwater was actually higher in 2004 than in 1995. In another $10-17 \%$ of villages, the average annual fall in the groundwater table was less than $0.25 \mathrm{~m} /$ year. In other words, in more than one-third to one-half of China's villages using groundwater over the last decade, groundwater resources have shown little or no decline since the mid-1990s. Although, (based on our data, most villages are in or nearly in balance) we are not arguing that groundwater problems do not exist. In fact, there are still a large number of villages in which the water table is falling. Before classifying these villages as being 
irrational groundwater resource exploiters (although some of them may be), it is important to remember that a village's water resources may not be overexploited even if the water table is falling. Given the fact that many of China's aquifers are fossil, by definition, any meaningful extraction will result in declining water levels. Hence, even under the most rationally planned groundwater utilization strategy, there will be a share of villages in China in which we should expect the water table to be falling. In addition, if we follow the Ministry of Water Resources (MWR) definition of serious overdraft, only $10 \%$ of villages using groundwater in the last decade have water tables that are falling at a rate faster than $1.5 \mathrm{~m} /$ year. Such a decline rate is not only serious, but also a crisis.

In summary, then, the point we want to make is that in many places indeed, in most places in northern China - it is possible that water resources are not being misused. However, we do not want to minimize the problems that are occurring in some places. There are a large number of rural areas in which the water table appears to be falling at a dangerously fast pace. Where the resource is being misused, steps will be required to protect the long-term value and use of the resource. However, it is important to realize that many of the required measures (discussed in the next section) will have associated costs - to obtain adoption and productivity, and to avoid reduced income. Because measures to counter overdraft are not needed in all villages, leaders should not take a one-size-fits-all approach so that they can avoid inflicting unnecessary costs on producers in communities where overdraft conditions do not exist.

\section{Subsequent effects of overdraft}

As the groundwater table falls, producers face a number of impacts; above all, of course, the cost of pumping rises. According to our data, for every meter by which the groundwater table falls, pump costs rise by $0.005 \mathrm{yuan} / \mathrm{m}^{3}$ (or about $2 \%$ of the mean level of pumping costs in 2004). In addition, wells may have to be replaced and the costs of investment increased, although in many cases new wells have been sunk for reasons other than the falling water table. The average cost of drilling a deep tube well $(90 \mathrm{~m})$ was more than five times the cost of drilling a shallow tube well $(37 \mathrm{~m})$. According to our data, well owners in China have sunk an enormous number of new wells in the last decade. On average, from 2002 to 2004, the typical groundwater-using village sank about 22 new wells, 5 deep and 17 shallow. Although a percentage of new wells ( 6 of the 22) were being installed because olds wells were abandoned, it should be noted that, according to the opinions of our respondents, only 2 of the 6 wells were abandoned because of the falling water table. In many cases, wells were replaced for other reasons (e.g. when a well structure collapsed).

Beyond the increases in pumping costs and well installation, there are also a number of other potential consequences of overdraft (Ministry of Water Resources and Nanjing Water Institute, 2004). One of the most commonly cited consequences is land subsidence. For example, in Hebei province alone, by 1995 more than $5000 \mathrm{~km}^{2}$ had subsided more than $600 \mathrm{~mm}$. In Tianjin municipality, the total exceeded $7000 \mathrm{~km}^{2}{ }^{17}$ Groundwater overdraft may also lead to 
the intrusion of seawater into freshwater aquifers (Ministry of Water Resources and Nanjing Water Institute, 2004). By the mid-1990s overdrafting allowed sea water to intrude and contaminate aquifers under more than $1500 \mathrm{~km}^{2}$ of land, especially in the coastal provinces of northern China such as Liaoning, Hebei and Shandong. The MWR has also been concerned about the impact of groundwater overdraft on desertification and depletion of stream flow that was previously supplied by natural groundwater discharge.

Although the consequences of overdraft are widely discussed in the literature and equated with China's water problems in general, interestingly none of these problems appears to be in any way associated with rural areas. According to our survey of more than 400 villages, no village leader ever reported that there was any land subsidence problem. Likewise, in no case did a village leader report that his or her village's groundwater was contaminated by sea water intrusion. Finally, there also was no evidence that villages that were using groundwater - both those that were drawing down their water table and those that were not - experienced a fall in cultivated area due to desertification. Clearly, although the attention that these problems get in the literature means that they are serious and require addressing, there appear to be no rural area problems.

\section{Other Problems with Groundwater}

\section{Groundwater pollution}

Both the literature on groundwater and our survey report a number of other problems that are not directly related to groundwater overdraft. For example, it has been widely reported in the press and in academic journals (e.g. Kendy et al., 2003) that pollution from municipal sewage has contaminated the groundwater of many villages in China. Part of the problem is created when farmers pump from effluent canals, using sewage-laced water on their fields. The recharge from irrigation with such water can affect the entire aquifer. Even when villages do not use the water for irrigation purposes, recharge from streams and riverbeds can contribute to groundwater pollution. According to the Ministry of Water Resources and Nanjing Water Resources Institute (2004), the groundwater resources of more than $60 \%$ of the 118 largest cities in China have contaminated groundwater.

Drawing on our survey (in which we asked leaders about their perception of pollution), we find that the scope of the problem is somewhat less and the main source of pollution is different than those reported in other sources; interviews with leaders in communities suffering from contaminated groundwater demonstrate that pollution is still a serious problem. According to our sample communities, the groundwater is polluted in $5.40 \%$ of the villages. However, unlike the villages around cities, which are mainly being affected by municipal sewage waste, respondents identified industrial pollution and runoff from mining operations as the most common source of pollution. In fact, of all the villages that reported contaminated groundwater, $95 \%(5.15 \%$ of the total 
number of villages) said that the main source of pollution was from industrial and mining waste water. Only $0.25 \%$ of all villages (or less than $5 \%$ of villages that report contamination) said that their groundwater was polluted by agricultural chemicals; none said it was due to urban sewage.

While the extent of the perception of rural groundwater pollution problem appears to be less serious than the urban/suburban problem, it is still serious. Extrapolating our results to all of northern China, we can estimate that more than 20 million rural residents living in 20,000 rural villages are using groundwater that has been contaminated by industrial runoff. Moreover, unlike their urban and suburban counterparts, most villages in China lack any type of drinking water processing facilities. In most cases, the pollution causing the problems in one rural community was created by the actions of industrial and mining facilities that belonged to some other community or economic agent. There is no clear advocate to force upstream communities either to stop polluting or to compensate downstream communities for the damage. Moreover, there is little funding for rural groundwater pollution abatement. In short, there is no incentive or means to address and/or curtail the activities that are polluting the groundwater of millions of rural communities.

\section{Soil salinization}

Across China, the appearance of salinized soil has been a widespread problem but, according to a number of sources, this problem has been improving in recent years, unlike many others. According to the Ministry of Water Resources and Nanjing Water Resources Institute (2004), more than 1 million square kilometers of China's land has become salinized over the past several decades. The majority of the most serious problems has occurred in the north-east, the northwest and in some places in the North China Plain. Despite the widespread nature of the problem, in recent years, the area affected by salinization has fallen. Ironically, it may be that the same forces diverting surface water away from agriculture and forcing producers to rely increasingly on groundwater may be the primary cause of such improvements. Without access to cheap and abundant surface water, which led to the salinized soil problem, the problem has gradually disappeared as farmers have turned to groundwater and the water table has fallen (Nickum, 1988)..$^{18}$

In our sample of villages, we find that the salinization of the soil is one of the most commonly reported problems, although, consistent with national statistics, it is improving over time. According to our respondents, in 2004, $16 \%$ of villages reported having some salinized soils. Since the process that caused the soil salinization does not affect all cultivated areas in a village, only $3.4 \%$ of cultivated area was reported to be affected. Moreover, the scope of soil salinization is improving over time. In 1995, $20 \%$ of villages reported salinized soils and $4.4 \%$ of cultivated area was affected. Hence, between 1995 and 2004, there was nearly a $25 \%$ reduction in the severity of the nation's soil salinization problem. 


\section{Managing China's Groundwater}

In this section we first examine the response - or more accurately, the lack of response - of the government to groundwater problems. We then track the response of producers - those at the community and individual household levels. As we will see, in contrast to officials, producers have responded sharply in many different ways.

\section{Regulating (or not) China's groundwater: the role of the government}

Over the last 50 years, China has constructed a vast and complex bureaucracy to manage its water resources. To understand the functioning of this system, it is important to first understand that, until recently, neither groundwater use nor water conservation has ever been of major concern to policymakers. Instead, the system was designed to construct and manage surface water to prevent floods, which have historically devastated the areas surrounding major rivers, and to effectively divert and exploit water resources for agricultural and industrial development. Historically, when attention was paid to water conservation, the emphasis was on surface water canal networks. Therefore, many of the most severe groundwater problems have not been directly addressed.

\section{Laws and measures}

Water policy is ultimately created and theoretically executed by the MWR. The MWR has run most aspects of water management since China's first comprehensive Water Law was enacted in 1988, taking over the duties from its predecessor, the Ministry of Water Resources and Electrical Power. The policy role of the MWR is to create and implement national price and allocation policy, and to oversee water conservancy investments by providing technical guidance and issuing laws and regulations to the subnational agencies (Lohmar et al., 2003).

In fact, officials in the MWR and in other ministries have spent time and effort in passing laws and regulations concerning groundwater management in rural areas. For example, according to China's national 1988 Water Law, the property rights of all underground water resources belong to the state. This means that the rights to use, sell and/or charge for water ultimately rest with the government. The law does not allow extraction if the pumping of groundwater is harmful to the long-term sustainability of the use of the resource.

Beyond formal laws, there have also been many policy measures set up in part to rationally manage use of the nation's resources. In most provinces, prefectures and counties there are formal regulations controlling the right to drill tube wells, the spacing of wells and the price of water when sold. The national government has also set up the necessary regulatory apparatus to allow for the charging of a water extraction fee (surface water and groundwater in urban areas).

Despite the plethora of laws and policy measures that have been created by officials, there has not been an equal effort put out in implementing them. Certainly, part of the problem is one of historic neglect. In fact, the delegation of 
groundwater management at the ministerial level is still relatively small. There are far fewer officials working on this division than in other divisions, such as flood control, managing surface water systems and water transfer. Moreover, unlike the case of surface water management (Lohmar et al., 2003), there has been no effort to bring management of aquifers that span jurisdictional boundaries under the ultimate control of an authority that can control the government and private entities that use water extracted from different parts of the aquifer. According to Negri (1989), when there is no single body controlling the entire resource, it becomes difficult to implement policies that attempt to manage the resource in a long-term, sustainable, more optimal manner.

Whether for lack of personnel or other difficulties in implementing the measures, inside China's villages few regulations have had any affect. For example, despite the nearly universal regulation that requires the use of a permit for drilling a well, less than $10 \%$ of the well owners surveyed obtained one before drilling. Only $5 \%$ of villages surveyed believed their drilling decisions needed to consider spacing decisions. Although price bureaus in every county were supposed to regulate the price for which groundwater was sold from one farmer to another, in only $8 \%$ of villages did this occur. Even more telling was that water extraction was not charged in any village; there were no physical limits put on well owners. In fact, it is safe to say that in most villages in China, groundwater resources are almost completely unregulated.

\section{Producer response}

Although China's central and regional governments currently have little control over groundwater in most parts of northern China, groundwater governance is not stagnant. In fact, when assessing the way groundwater is managed, the way farmers gain access to water and the way technology is being used to conserve the resource, the sector can be considered to be extremely dynamic. In this section, we examine three sets of issues: the privatization of tube wells, the emergence of groundwater markets and the adoption of new, water-saving technologies.

\section{Privatization}

Among any individual features of northern China's groundwater economy, the privatization of tube wells is perhaps the most prominent. Before the rural reforms in the 1960s and 1970s, township governments and village leadership councils financed, owned and managed most tube wells. In most villages individual farmers at most contributed their labour for tube well construction. Financed primarily by collective retained earnings, commune, brigade and team cadres were largely responsible for arranging for well-drilling companies run by the water resource bureau to sink tube wells. Pumps in the pre-reform era all came from either the water resource bureau pump supply company or the state-run local agricultural inputs corporation.

Soon after the general economic reforms began in the early 1980s, however, the ownership of China's tube well began to shift sharply. According to 
our survey in Hebei province in the late 1990s, collective ownership accounted for $93 \%$ of all tube wells in the early 1980s. Throughout the late 1980s and 1990s, however, the collective ownership of tube wells diminished. During this period the share of private tube wells increased from $7 \%$ to $64 \%$. Data from the NCWRS largely support these findings. Tube well ownership in our study area, representing all of northern China, has also shifted sharply from collective to private (Table 3.3). In 1995, collective ownership accounted for 58\% of tube wells in the average groundwater-using village. From 1995 to 2004, however, the collective ownership of tube wells diminished and accounted for only $30 \%$ of wells in 2004. In contrast, during the same period the average share of private tube wells increased from $42 \%$ to $70 \%$.

Our interviews also revealed that the rise of privately financed investment means that the shift of tube well ownership is the result of the establishment of new tube wells rather than ownership transfers of collective tube wells. Due to the fall of the groundwater table and lack of maintenance on pumps and engines, a number of collective tube wells became inoperable during the last two decades and the absolute number of collective tube wells fell. During this time, the number of private wells increased rapidly.

\section{Groundwater markets}

As tube wells and the accompanying pumping equipment have come under the control of private individuals, access to groundwater for those farmers who do not own and operate their own wells has become a new issue. In fact, these markets have not always existed. In the 1970s and 1980s, when most wells were owned and operated by collective ownership, in almost all villages simple rules governed water allocations; most of the rules were based on a system in which all individuals were provided with water in an equitable way. In some villages, the collective ownership provided water free or at a subsidized rate. In the early period after reform, however, for a number of reasons the traditional institutions began to break down (see e.g. Wang et al., 2005). In today's world in which most wells are owned by some, but not all, farmers there must be some way to transfer water from those with wells to those without.

In response to the demand for water in an environment increasingly dominated by private and privatized wells, following a pattern similar to that observed in South Asia (Shah, 1993), groundwater markets have begun to emerge in recent years as a way for many producers in rural China to gain access to

Table 3.3. Changes of well ownership from 1995 to 2004 .

\begin{tabular}{lccccc}
\hline & \multicolumn{2}{c}{ All wells } & & \multicolumn{2}{c}{ Private wells } \\
\cline { 2 - 3 } \cline { 5 - 6 } & Collective & Private & & Shareholding & Individual \\
\hline Share of wells (\%) & 58 & 42 & & 53 & 47 \\
1995 & 30 & 70 & & 38 & 62 \\
2004 & 30 & & & & \\
\hline
\end{tabular}


groundwater. ${ }^{19}$ In the 1980s, groundwater markets were almost non-existent. Indeed, according to the NCWRS, only $21 \%$ of villages had groundwater markets in 1995. By 2004, however, tube well operators in $44 \%$ of villages were selling water. Across all villages about $15 \%$ of private tube well owners sold water. Although groundwater markets exist in less than half of northern China's villages, the numbers are still significant: farmers in more than 100,000 villages are accessing water through groundwater markets. Moreover, in villages that have groundwater markets, these markets play an important role in transferring large volumes of water to a large number of households. ${ }^{20}$

\section{Household and village adoption of water-saving technology}

Another possible response to perceived water shortage is the adoption of new cultivation techniques and technologies. Our survey covered three sets of technologies: traditional technologies (agronomic-based, highly divisible ${ }^{21}$ ); household-based technologies (highly divisible, low fixed cost, requiring little collective action), which were generally practiced by farmers in pre-People's Republic of China; and community-based technologies (high fixed costs, requiring collective action for adoption and maintenance). The adoption paths of these three different water-saving technologies trace three distinct sets of contours. Moreover, the general path of each technology within each major category - traditional, household-based and community-based - tends to follow the trajectory of the other similar technologies within its category. In this section, we track the adoption with one set of measures - a village-based set of measures in which a village is considered to have adopted a technology if at least one plot or farmer in the village uses the technology. In another study (Blanke et al., 2005), we also examine a measure of area of adoption (which gives largely the same pattern of results).

As the name implies, according to our data, traditional water-saving technologies have been used for many years (Fig. 3.5, top set of lines). The strongest distinguishing characteristic of traditional water-saving technologies is that they were being used in a relatively large number of China's villages even in the early 1950s. For example, in 1949 farmers in 55\% of northern China villages were already leveling their land. During the reform period, the adoption of traditional technologies grew slowly, in part because traditional technology adoption rates were already high in the pre-reform and early reform era.

In contrast, household-based technologies have taken a different technological adoption path over the last 50 years (Fig. 3.3, middle set of lines). Although it is difficult to distinguish exact levels of adoption from Fig. 3.2 (the paths are too tightly bunched), household-based water-saving technology adoption rates were all low in 1949, ranging from 1\% (surface pipe) to $10 \%$ (retain stubble/low till). Unsurprisingly, due to the relative abundance of water and the nature of farming at the time (collective-based with few incentives to maximize profits), household-based technology adoption rates at the village level remained low over the next 30-40 years. It was not until the early $1990 \mathrm{~s}$ that these adoption rates soared. By 2004, farmers in at least $45 \%$ of villages were using each type of household-based water-saving technology mentioned in the Appendix. 


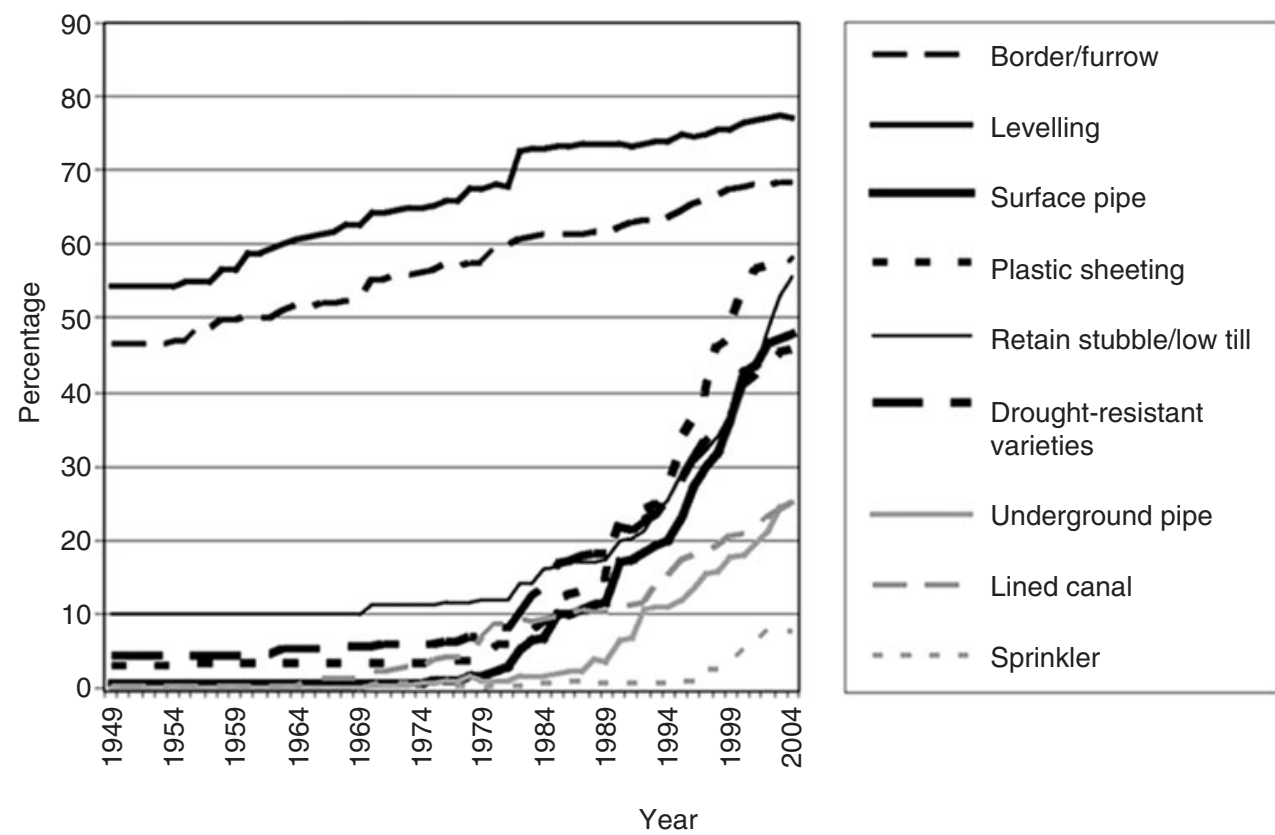

Fig. 3.5. Share of villages adopting water-saving technologies over time.

Finally, although the basic pattern of community-based technology adoption follows the same fundamental trend as household-based technologies, these paths start lower and rise at a slower rate (Fig. 3.3, lowest set of lines). Between the 1950s and 1980s, like household-based technologies, adoption rates were low. By the beginning of the reforms in the mid-1980s, the highest village-level adoption rate of a community-based technology (lined canals) was only $10 \%$; on average the level of adoption of community-based technologies during the mid-1980s was around 5\%. By 2004, as in the case of householdbased technologies, the rate of adoption rose sharply relative to previous years. Because community-based technologies started from a lower level and rose less by 2004, the village-based measures still show that, on average, only about $20 \%$ of communities had adopted community-based technologies.

Although it is unclear, based on these descriptive contours, what is driving the adoption path of community-based technologies, it is likely that there are two sets of forces that are at once encouraging and holding back adoption. On the one hand, the rising scarcity of water resources is almost certainly pushing up demand for community-based technologies. On the other hand, the predominance of household farming in China (Rozelle and Swinnen, 2004) and the weakening of the collective ownership's financial resources and management authority (Lin, 1991) have made it more difficult to gather the resources and coordinate the effort needed to adopt technologies that have high fixed costs and involve many households in the community. In contrast, 
household-based technologies may be more widely adopted due to relatively low fixed costs, divisibility and minimal coordination requirements.

\section{Conclusions}

The primary goal of this chapter was to sketch a picture of China's groundwater water economy, with a focus on rural areas. Indeed, in our efforts to do so, we have generated a number of empirical-based findings that, at the very least, may help to clarify a number of misperceptions on which past discussions of China's water resources were sometimes based. China has some of the most abundant groundwater resources in the world. Over the last 2-3 decades in a large portion of China's localities, these resources have begun to be tapped. According to our results, however, there are still a significant number of areas that have undeveloped groundwater resources, even in the north-eastern areas, commonly believed to be generally overexploited.

In areas that have begun to use their groundwater resources, we have been able to paint a somewhat unorthodox picture. While there are serious groundwater problems (in around $10 \%$ of villages, the groundwater table fell by more than $1.5 \mathrm{~m} /$ year), including groundwater overdraft in some areas of northern China, in many other areas - indeed in more than one-third to one-half of China's villages using groundwater in northern China - groundwater resources have not diminished at all levels or are declining at less than $0.25 \mathrm{~m} /$ year over the last decade. In other words, the groundwater economy is heterogeneous, and as such, in dealing with policy in the future, considering the differences is important.

We also believe that we have been able to lay out a clear pattern of actual responses by major actors that will help to clarify the challenges for managing groundwater in the coming years. In short, government officials have done little to control the extraction of groundwater in rural China. Producers, especially individual farmers, on the other hand, have been responsive. Farmers have taken over control of most of the well and pump assets; they are increasingly taking on responsibility of transferring water from those who have wells to those who demand water. They are also figuring out ways to conserve the scarce resources. ${ }^{22}$ Hence, the policy implication of all these results is clear. There needs to be a multistep response by officials. First, they need to determine where serious overdraft is occurring and where it is not. Attention then needs to be paid to the areas in which there is a problem. Policy must recognize that, with proper incentives, farmers will respond by saving water and transferring the resources from those who have it to those who need it. ${ }^{23}$ Hence, if formulas can be designed to implement price-based policies or some other set of policies that make the scarcity of water more evident, farmers will respond. Such policies will not be easy to implement as they require a lot of information on the nature of the resource. In order to avoid negative income effects on those farmers who would have to pay more for water, it may also require complex transfer schemes in which farmers who are being charged for water and are being forced to cut back at the same time can be compensated in some way to try to minimize or offset the higher 
water fees. The transaction costs in such a system must also be considered. In some areas, it is possible that quantity control could work more efficiently than price-based control.

\section{Acknowledgements}

The authors would like to thank Mark Giordano, Tushaar Shah and Lijuan Zhang for their insights and helpful suggestions. We acknowledge the financial support from the National Natural Sciences Foundation (70021001) in China, the International Water Management Institute, the Australian Center of International Agricultural Research (ADP-200-120), the Food and Agriculture Organization of the UN and the Comprehensive Assessment on Water Management in Agriculture. Scott Rozelle is a member of Giannini Foundation.

\section{Notes}

1 The 12 provinces are: Heilongjiang, Jilin, Liaoning, Inner Mongolia, Hebei, Shandong, Shanxi, Henan, Shaanxi, Qinghai, Ningxia and Gansu. The two municipalities are Beijing and Tianjin. In this analysis, because of the lack of information on provinces in the extreme western areas of China, we do not include Tibet or Xinjiang in northern China.

2 Groundwater is also very important in urban water supply in northern China.

3 In Hebei province, where county-level groundwater overdraft statistics are available, the scarcity categories were defined according to a Ministry of Water Resource publication that categorized provinces by scarcity (which almost certainly is related to the degree of annual overdraft). In the remaining provinces, all four scarcity indices were defined according to the percentage of irrigated area as follows: very scarce (between $21 \%$ and $40 \%$ ), somewhat scarce (between $41 \%$ and $60 \%$ ), normal (more than $61 \%$ ) and mountain and desert (less than $20 \%$ ). Within each of the scarcity strata, we sampled two or three counties; of all the counties in the mountainous and desert areas, we chose one county.

4 The information that we collected comes from estimates provided to enumerators from village leaders based on their experience during the survey. For some technical data (data on water levels, water quality, soil salinity, etc.), although the village leaders do not have access to scientific measurements, they are readily able to state their perceptions on these issues. We believe, in many cases, that the information is fairly accurate. Even in the cases when information on the level of a variable for a given year may not be absolutely accurate (e.g. the salinity level of the water), due to the fact that they have been living and working in the village for many years, we believe that they are able to provide accurate estimates on the trends of these variables. Because these are based on the experience of village leaders, their response rates were high. In fact, for most variables the response rate was $100 \%$, meaning our data are not subject to dropout bias.

5 In north China, almost all provinces have both mountainous areas and flat plains; therefore, it is hard to describe which regions are mountainous and which flat.

6 Although we have not asked the reason that why farmers only extract groundwater from deep aquifers, based on our experience in the field, it should be due to exhausted or unusable shallow aquifers. 
7 We need more investigation to explore the reason in the future.

8 One of the important characteristics of the rural economic reforms in China is that land was distributed evenly to individual farm households. After the rural reforms, although land ownership was still collective, land use and income rights were transferred to individual farm households. Before the rural reforms, communes and brigades/teams (i.e. village collectives) financed most tube wells. After reform, the fiscal revenue position of many villages declined. More importantly, after the early 1980s the policy constraints that originally limited the scope of private activities were gradually relaxed and this resulted in the development of private tube wells.

9 Compared with the allocation of total water use to non-agricultural sectors, groundwater allocation to these sectors appears to have increased more rapidly. In 1997, non-agricultural sectors used $46 \%$ of total groundwater resources, while they only used $31 \%$ of total water resources (see Table 3.1, row 4).

10 Although maize is grown during the rainy season, and so the crop generally does not require as much irrigation as wheat (which is grown mostly during the dry season), irrigation can still play an important role in increasing maize productivity (Huang et al., 2006). In North China, irrigation is supplementary.

11 According to Wang et al. (2006), the expansion of tube wells does not necessarily mean that there is an expansion in water consumption. However, according to our data, a significant share of the new wells is located in areas that are allowing for the expansion of cropping area, increased intensity of cropping and rising yields. Hence, while not all of the rise in wells will result in increased consumption of water, a part of it will.

12 This indicates that due to the decline in the groundwater table, it requires more power to extract water.

13 There are also several other minor types of aquifers that are being overdrafted, which account for about $7000 \mathrm{~km}^{2}$.

14 The definition of overdraft here is from MWR in China. It is important to note, however, that there are other definitions. For example, Kendy points out that the MWR does not accurately define 'overdraft'. In a sustainable system, groundwater recharge should equal discharge over time. Extraction (groundwater pumping) is only a small part of total discharge from an aquifer. Other parts include natural discharge to rivers (which explains why rivers flow even long after rain and snow stop falling), and natural discharge to wetlands, lakes and plants. If extraction (groundwater pumping) exceeds recharge, all those other components of groundwater discharge would cease. Overdraft is better defined by long-term water level declines.

15 According to a comprehensive survey completed by the Ministry of Water Resource in 1996, groundwater overdrafting is a widespread problem and may be getting worse.

16 In our survey we asked village leaders about the average level of groundwater depth during the year and the 'static' level of the groundwater. We explained that the static level of the water table is the level that exists immediately prior to the irrigation season (e.g. in the North China Plain this would be around the month of March). According to our respondents, there were differences in the statistics on the changes in the groundwater table when using average or static groundwater levels. According to our data, the static level produced numbers that suggested there were fewer villages in which the groundwater table was falling.

17 Land subsidence mainly occurs in urban areas.

18 Salinization is caused by different factors, and responds to different solutions in different settings. Over time, continued groundwater use is likely to increase soil and water salinization. Each time groundwater is 'recycled' through the pumping and reinfiltration process, it becomes more saline. 
19 We define groundwater markets as localized, village-level arrangements through which owners of tube wells sell pump irrigation services to other farmers of the village (i.e. they sell water to other farmers from their wells for use on crops). In this chapter, we are only going to examine 'private' water markets. In other words, we will examine the nature of groundwater markets that are being driven by individuals and groups of individuals that sink wells. In making such a definition, we are assuming that when village leaders (the collective owners) provide water to villagers, this is being done under non-market conditions.

20 Groundwater markets in northern China are not necessarily 'competitive' and may be more accurately characterized by captive selling. When farmers buy water through groundwater markets, they not only pay for operating costs, but also pay a little service cost that contributes to profit for the operators or owners.

21 Here 'highly divisible' means that individual farmers can adopt the technology by themselves.

22 Some researchers (Kendy et al., 2004) argue that farmers are figuring out ways to reduce pumping without reducing crop production. Thus, they are conserving electricity, but not water.

23 Some researchers (Kendy et al., 2004) argue that policies must ensure that water is actually saved (i.e. irrigated area decreases). So long as crop production stays the same, no water will be saved and any 'transfers' will only exacerbate the problem.

\section{References}

Blanke, A., Rozelle, S., Lohmar, B., Wang, J. and Huang, J. (2005) Rural Water-Saving Technology Adoption in Northern China: An Analysis of Survey Results. Selected paper prepared for presentation at the American Agricultural Economics Association Annual Meeting, Providence, Rhode Island, 24-27 July 2005.

Brown, L. and Halweil, B. (1998) China's water shortages could shake world food security. World Watch 11(2), 10-18.

Chen, C., Pei, S. and Jiao, J. (2003) Land subsidence caused by groundwater exploitation in Suzhou City, China. Hydrogeology Journal 11, 275-287.

China National Statistical Bureau (2000) China Statistical Yearbook. China Statistical Publishing House, Beijing.

China National Statistical Bureau (2004) China Statistical Yearbook. China Statistical Publishing House, Beijing.

Hoffman, G.J. and Durnford, D.S. (1999) Drainage design for salinity control. In: van Schilfgaarde, J. and Skaggs, W. (eds) Agricultural Drainage. American Society Agronomy Monograph, pp. 579-614.
Hu, R. (2000) A Documentation of China's Major Grain Varieties. Working Paper, Chinese Center for Agricultural Policy, Chinese Academy of Sciences, Beijing.

Huang, Q., Rozelle, S., Wang, J. and Huang, J. (2006) Irrigation, agricultural performance and poverty reduction in China. Food Policy 31(1), 30-52.

Kendy, E., Molden, D.J., Steenhuis, T., Liu, C. and Wang, J. (2003) Policies Drain the North China Plain: Agricultural Policy and Groundwater Depletion in Luancheng County, 19492000. IWMI Research Report 71.

Kendy, E., Zhang, Y., Liu C., Wang, J. and Steenhuis T. (2004) Groundwater recharge from irrigated cropland in the North China Plain: case study of Luancheng County, Hebei Province, 1949-2000. Hydrological Processes 18, 2289-2302.

Lin, J. (1991) Prohibitions of factor market exchanges and technological choice in Chinese agriculture. Journal of Development Studies 27(4), 1-15.

Lohmar, B., Wang, J., Rozelle, S., Huang, J. and Dawe, D. (2003) China's Agricultural 
Water Policy Reforms: Increasing Investment, Resolving Conflicts and Revising Incentives. Agriculture Information Bulletin \#782, Economic Research Service, USDA.

Ministry of Land Resources (2005) Report on Groundwater Resources and Environment Investigation in China, finished by Ministry of Land Resources, Beijing.

Ministry of Water Resources (2000) China Water Resources Bulletin.

Ministry of Water Resources (2002) China Water Resources Bulletin.

Ministry of Water Resources and Nanjing Water Institute (2004) Groundwater Exploitation and Utilization in the Early 21st Century, China Water Resources and Hydropower Publishing House, Beijing.

Negri, D.H. (1989) The common property aquifer as a differential game. Water Resources Research 25(1), 9-15.

Nickum, J.E. (1988) All is not wells in North China: irrigation in Yucheng County. In: O'Mara GT (ed.) Efficiency in Irrigation. The World Bank, Washington, DC, pp. 87-94.

Nickum, J.E. (1998) Is China living on the water margin? The China Quarterly (156), 880-898.

Rozelle, S. and Swinnen, J. (2004) Success and failure of reforms: insights from transition agriculture. Journal of Economic Literature 42(2), 404-456.

Sakura, Y., Tang, C., Yoshioka, R. and Ishibashi, $H$. (2003) Intensive use of groundwater in some areas of China and Japan. In: Llamas, R. and Custodio, E. (eds) Intensive Use of Groundwater: Challenges and Opportunities. A.A. Balkema, Rotterdam, The Netherlands.

Shah, T. (1993). Groundwater Markets and Irrigation Development: Political Economy and Practical Policy. Oxford University Press, Bombay, India.

Shi, Y. (2000) Groundwater Development in China. Paper for the Second World Forum, The Hague, 17-22 March 2000.

Smil, V. (1993) China's Environmental Crisis: An Inquiry Into the Limits of National Development. M.E. Sharpe, Armonk, NewYork.

Tang, K. (1999) Strategic Options for the Water Sector, TA NO 2817-PRC, Vol. 3, Working Paper 7, July 1999.

Wang, J., Huang, J. and Rozelle, S. (2005) Evolution of tubewell ownership and production in the North China Plain. Australian Journal of Agricultural and Resource Economics 49(2), 177-195.

Wang, J., Huang J., Huang, Q. and Rozelle, S. (2006) Privatization of tubewells in North China: determinants and impacts on irrigated area, productivity and the water table. Hydrogeology Journal 14, 275-285.

World Bank (1997) At China's Table. Monograph, The World Bank, Washington, DC.

You, S. (2001) Agricultural adaptation to climate change in China. Journal of Environmental Sciences 13(2), 192-197. 


\section{Appendix: Types of Water-saving Technologies}

During our survey of leaders and water managers in more than 400 villages, we discovered that there are many types of water-savings technologies being used in northern China. For the purposes of this chapter, the term water-saving technology encompasses a wide variety of irrigation techniques and agricultural production practices. For analytical convenience, we have divided the list of technologies into three groups: traditional, household-based and community-based. In the rest of the chapter, we are excluding any discussion of a series of novel water-saving technologies (e.g. drip, intermittent irrigation, and chemicals and drugs) because across our sample, they had very low levels of adoption (i.e. nearly zero).

Our use of the term 'water-saving' is limited to perceived field-level applied irrigation savings. We understand that in the case of many technologies that we are considering, their adoption may not save water when net water use is measured on a basin scale. The real, or basin-wide, water-saving properties of each technology depend not only on the technical features of the technology, but also on the hydrology of the system and the economic adjustments to production that are associated with adoption of the technology.

Traditional technologies include border and furrow irrigation and field levelling. We have grouped these technologies because they are widely adopted and because village leaders in a majority of villages report adopting these techniques well before the beginning of agricultural reform in the early 1980s. These irrigation methods have relatively low fixed costs and are separable in the sense that one farm household can adopt the practice independent of the action of neighbours.

Household-based technologies include plastic sheeting, drought-resistant varieties, retain stubble/low till and surface-level plastic irrigation pipe. We have grouped these technologies because they are adopted by households (rather than villages or groups of households), have relatively low fixed costs and are highly divisible. Typically, adoption of these technologies is more recent than adoption of the traditional technologies.

Community-based technologies include underground pipe systems, lined canals and sprinkler systems. We have grouped these technologies because they tend to be adopted by communities or groups of households rather than by individual households. In most applications, they have large fixed costs and often require collective action or ongoing coordination of multiple households. 